DOI: $10.14451 / 1.174 .122$

\title{
ИННОВАЦИОННЫЕ МАРКЕТИНГОВЫЕ ТЕХНОЛОГИИ
}

\author{
(c) 2019 Удальцова Наталья Леонидовна \\ кандидат экономических наук, доцент департамента менеджмента \\ Финансовый университет при Правительстве Российской Федерации, Россия, Москва \\ E-mail: udaltsova.nl@yandex.ru \\ (c) 2019 Алышева Алиса Вадимовна \\ студентка факультета «Социология и политология», \\ направления «Реклама и связи с общественностью», группы РСO18-4 \\ Финансовый университет при Правительстве Российской Федерации, Россия, Москва \\ E-mail: alysheva.alisa@mail.ru
}

В данной статье рассмотрены различные виды инновационного маркетинга и инновационные способы продвижения. Показаны новейшие инновационные разработки в сфере маркетинга, проанализированы их актуальность на сегодняшний день и потенциал в будущем. Отдельное внимание в работе акцентируется на маркетинговых технологиях в интернет-сфере, обоснована взаимосвязь маркетинговых инноваций и интернета, а также выявлены их преимущества и недостатки. Целью данной работы является выявление роли инновационных маркетинговых разработок в современной жизни на основе анализа их разновидностей и применения в практике.

Ключевые слова: маркетинг, инновации, инновационный маркетинг, интернет, интернетмаркетинг.

\section{Введение}

На сегодняшний день инновационные маркетинговые технологии являются необходимыми аспектами повышения эффективности, конкурентоспособности и продаваемости той или иной продукции. Современное состояние мирового рынка постоянно развивается, находясь на маркетинго-инновационном этапе и именно поэтому инновационная деятельность имеет огромное значение. Её особая роль отмечается в областях, использующих высокий интеллектуальный вклад наряду со стоимостью товаров и услуг. Концепция инновационного маркетинга заключается в постоянном совершенствовании методов маркетинга, производимой продукции, а также в повышении рентабельности производства и конкурентных сторон предприятия. Стоит отметить, что инновации являются не только составляющими элементами маркетинга, но и средствами выживания на рынке.

\section{Понятие инновационного маркетинга}

Итак, смысл инноваций заключается в новшествах, выраженных в товарах, технологиях, изобретениях, результатах научных исследований и прочих факторах, которые внедряются на рынок посредством производства. Однако, понятия инновации в России и зарубежных странах различаются между собой, что позволяет воспринимать их используя несколько сторон и точек зрения. Так, российское определение рассматривает инновационную деятельность чаще всего как конечный результат инноваций. Иными словами, инновация в этом ключе означает какое-либо новшество, внедрённое на рынок. Зарубежный опыт рассматривают инновации как интеллектуальную деятельность, процесс изменений и создания новой продукции, технологий, методов. То есть инновационный продукт в их понимании - это результат творческого процесса. Если постараться объединить упомянутые выше понятия в единое целое, то инновацию можно определить как знания, выраженные в виде новых или модернизированных товаров и услуг, а также технологий и производственных процессов, имеющих коммерческую направленность.

Инновационный маркетинг содержит множество критериев, определяющих цели, свойства, мотивы и процесс инновационной деятельности. Основными из них являются:

- Проведение научных исследований, создающих идеи для новшеств;

- Создание и распространение организационных и управленческих решений, реализующих новшества;

- Коммерциализация новшества, отобража- 
ющая принятие его рынком;

- Научно-технические инновационные разработки;

- Воплощение и применение новшеств в практике;

- Предоставление необходимого сырья и материалов, способствующих разработке новых товаров;

- Обучение, квалификация и тщательный отбор персонала;

Разновидности инновационного маркетинга

На сегодняшний день маркетинг, основанный на инновационных подходах составляет огромную конкуренцию традиционному маркетингу, в связи с тем, что большинство населения активно пользуется современными технологиями и проживает в информационном обществе. Эволюция инновационного маркетинга связана прежде всего с тем, что постоянно формируются новые виды маркетинга, практикующие нетрадиционные подходы рыночной деятельности различных предприятий. Таким образом, можно выделить основные актуальные направления: нейромаркетинг, сенсорный маркетинг, когнитивный маркетинг, event-маркетинг, маркетинг взаимоотношений, а также интернет-маркетинг, включающий в себя мобильный, вирусный, SMM, SMO, VRM, SMS- и buzz-маркетинг.

Нейромаркетинговая концепция является одним из наиболее распространённых и ярких видов инновационного маркетинга. Нейромаркетинг был разработан в 1990-х годах в Гарвардском университете. Он определяется как набор различных методов, изучающих поведенческие и эмоциональные реакции покупателей, и воздействие на них путём использования маркетинговых, когнитивно-психологических и нейрофизиологических технологий и разработок. Данный метод использует индивидуальные подходы к потребителям используя обширный инструментарий, от магнитно-резонансной томографии до регистрации движения глаз с помощью датчиков (айстрекинг). Так, основные цели нейромаркетинга заключаются в разработке способов, определяющих объективные предпочтения покупателей без использования субъективных методов сбора информации и в создании рекламы, склоняющей покупателей к приобретению тех или иных товаров и услуг до осознания и формирования своей позиции. Существует масса методов нейромаркетинговых исследований, но поскольку человек восприни- мает 90\% информации визуально, стоит рассмотреть один из самых известных запатентованных способов - ZMET (Zaltman Metaphor Elicitation Teqhnique) или метод извлечения метафор Залтмена. Данный способ исследует подсознание человека с помощью определённых наборов картинок. Подобранные изображения стимулируют у потребителей положительные эмоции и вызывают скрытые метафоричные образы, подталкивающие к покупке. Далее конструируются специальные коллажи, использующиеся в дальнейшем в рекламных роликах и изображениях, которые люди видят каждый день. Технология ZMET используется крупнейшими компаниями, в число которых входит “Coca-Cola”, “Nestle”, "Procter\&Gamble”, “General Motors” и прочие. Также способ подобранных картинок используется в методе магнитно-резонансного сканирования, однако реакцию клиента в этом случае определяют не с помощью беседы с психологом, а благодаря снимкам его мозга.

Ещё одним инновационным направлением является сенсорный маркетинг (чувственный маркетинг, маркетинг ощущений), который способен воздействовать на все органы чувств человека: обоняние, осязание, слух, зрение и вкусовое восприятие. Так, теория чувственного маркетинга заключается в том, что предлагаемая брендом продукция должна звучать, иметь свой уникальный запах, вкус или давать определённые тактильные ощущения. Отличительная черта данной маркетинговой разработки заключается в том, что бренд воздействует на аудиторию не столько посредством рационального восприятия, сколько благодаря эмоциональным факторам и без непосредственного контакта в точках продаж. В магазинах, кафе, торговых центрах не случайно играют конкретные мелодии, в кофейнях не случайно предлагают попробовать напитки со вкусом розы или лаванды, а проходя мимо пекарен, люди тоже не случайно улавливают запах свежевыпеченных изделий.

Наибольшее внимание в сенсорном маркетинге уделяется аромамаркетингу, когда в какой-либо точке продаж ароматизируется воздух с целью создания благоприятной обстановки для покупателя, которая впоследствии стимулирует его на приобретение товара. Впервые, о запахе как о полноценном инструменте маркетинга заговорили датский маркетолог Мартин Линдстром, создавший теорию маркетинга ощущений, и американский психиатр Алан 
Хирш, выявивший, что запахи способны повлиять на поведение человека и вызвать какие-либо действия с его стороны. Маркетинговые исследования демонстрируют, что благодаря приятным ароматам покупатели задерживаются в магазинах на 15-20\% дольше, чем обычно. Это благоприятно сказывается на уровне продаж компании, так как использование аромамаркетинга способствует побуждению покупателей к импульсивным покупкам, а также создаёт фирменный имидж бренда, выделяющий его среди конкурентов. К примеру, магазины одежды «Massimo Dutti» имеют фирменный запах сандалового дерева, кофе и лимона, магазины «Hugo Boss» используют цветочные ароматизаторы, чаще всего отдавая предпочтение лилиям. В магазинах, продающих товары из кожи или кожзаменителя, часто можно почувствовать насыщенный запах натуральной кожи, способствующий улучшению представления об уровне качества товара, а в местах быстрого питания (McDonald's, KFC, Burger King и пр.) или пекарнях всегда пахнет вкусной едой, разыгрывающей аппетит, даже если до этого человек не ощущал чувство голода. И всё это - тоже заслуги распылённых ароматизаторов.

Существует также когнитивный маркетинг, разрабатывающий нетипичные подходы к деятельности предприятий на рынке и воздействующий на поведение потребителя. У данной разновидности существуют две интерпретации. Первая, более классическая, означает, что когнитивный маркетинг - это наука, совмещающая маркетинг и психологию. Основными принципами такого маркетинга являются социальная коммуникация, программирование потребительского поведения, а также достижение и поддержание когнитивного баланса. Понятие когнитивного баланса было разработано психологом Фрицом Хайдером. Согласно ему, когнитивный баланс является фундаментом маркетинговых технологий и коммуникаций, а также он включает в себя характеристики полноценной коммуникативной личности и позиционируется как главная причина формирования технологий потребления и сбыта. Личность, при этом, выдвигается на первое место и характеризуется как основной носитель знаний и навыков. Ещё одно значение когнитивного маркетинга заключается в понятии когнитивной технологии - компьютерном алгоритме, симулирующим обработку сенсорной информации мозгом человека [8]. И такие когнитивные технологии могут частично или полностью заменить когнитивные функции людей. Суть заключается в том, что разрабатывается алгоритмическая компьютерная модель, способная обрабатывать такие входные данные сенсорной информации, как оттенки, тексты, эмоции и прочие факторы восприятия. В качестве примера можно привести случай, когда российские специалисты вместе со швейцарским банком работали над кейсом, согласно которому нужно было представить банк как современный и продемонстрировать его высокотехнологичные стороны, сохранив при этом традиционные ценности. В итоге разработчики приняли интересное решение: они проанализировали многочисленные картины Рембрандта и опираясь на фрагменты и детали данного анализа, создали картину «Следующий Рембрандт», которая фактически не существует, но теоретически могла бы быть. Во время анализа специалисты старались понять, какой техникой пользовался художник, какие мазки клал, какие пропорции соблюдал и так далее. Далее, они воспроизвели эту письменную когнитивную функцию при помощи компьютера. Тем не менее, созданная ими картина воспринималась как нарисованная, а не напечатанная. Данный кейс выиграл в «Каннских львах» в 2017 году.

Инновационные маркетинговые технологии в интернет-сфере

Маркетинговая интернет-среда является в настоящее время крупнейшей маркетинговой площадкой для продвижения тех или иных товаров, ведь интернет применяется абсолютно во всех сферах человеческой деятельности. Интернет-маркетинг включает в себя множество цифровых ресурсов, видов, характеристик, способов продвижения и так далее. Ниже будут рассмотрены некоторые разновидности цифрового (интернет) маркетинга.

Итак, мобильный маркетинг совмещает в себе несколько приёмов интернет-маркетинга с помощью использования мобильного телефона. Впервые, использование мобильного маркетинга в 2001 году предложила единственная на тот момент компания, занимающаяся мобильной рекламой - «Empocket». Уже спустя два года, осознав, что данное направление перспективно, была создана Ассоциация мобильного маркетинга. В общем, суть мобильного маркетинга заключается в распространении мобильной рекламы с помощью интернет-ресурсов. Такая 
реклама имеет множество преимуществ. К примеру, общий коэффициент отклика в мобильном интернете в 10 раз превышает коэффициент отклика в проводном. Также, показатель запоминаемости этой рекламы составляет 60\%, что демонстрирует достаточно высокий уровень. Ещё стоит отметить, что показатель доходов мобильной рекламы значительно выше, чем доходность на более традиционных площадках, а расходы на её размещение - напротив, ниже. В 2018 году специалисты «IAB Russia» провели исследование рынка мобильной рекламы в России за 2017/2018 год [3]. Так, по их показателям, в 2017 году объём российского рынка мобильной рекламы составил около 62-70 млрд. рублей (в 2008 году показатели варьировались в пределах 300-375 млн. рублей, в 2010-2-3 млрд. рублей). Мобильная реклама охватила около 40\% бюджета на всю интерактивную рекламу и заняла третье место по объему бюджета среди медийных каналов после телевидения и другой интернет-рекламы.

Также, к области интернет-маркетинга и мобильного маркетинга в частности можно отнести SMS-маркетинг, до недавнего времени являвшийся одним из наиболее распространённых методов установления визуальной коммуникации с помощью телефона, пока его не вытеснили более передовые технологии. SMS-реклама отличается тем, что персонально доставляет абоненту информацию и имеет сравнительно небольшой процент уклонения. Так, SMS-маркетинг состоит из рекламных рассылок, включающих в себя различные акции, розыгрыши, викторины, конкурсы, а также опросы и голосования.

Несомненно, популярной разновидностью инновационного маркетинга является вирусный маркетинг (ViralAd), который зародился в 1996 году в США. Вирусный маркетинг определяется как массовое, запоминающееся и краткосрочное продвижение товаров, сутью которого является не вызывание негативных эмоций и навязывание своей продукции потребителю, а указание пути, ведущего клиента к нужному товару или услуге с помощью ненавязчивых советов. Впоследствии, потребитель транслирует информацию окружающим и делает это на добровольной основе, в связи с личным интересом. Сама эта информация не воспринимается клиентами как реклама. В их глазах это выглядит больше как досуг или способ развлечения. К вирусному контенту можно отнести видео, фото, флеш-игры, какие-либо тексты (статьи, новости, анекдоты и пр.). Идея стратегии вирусного маркетинга заключается в том, что человек попадает под воздействие рекламы и ненамеренно «заражается» целью распространить контент и стать ретранслятором полученной информации. Это происходит, когда он, к примеру, пересылает друзьям забавные ролики или картинки, делится ссылками, принимает участие в каких-либо играх или конкурсах, посредством чего и происходит коммуникация с брендом. Для продвижения своей товарной линейки, вирусный маркетинг используют такие крупные компании, как «Apple», «Mercedes-Benz», «Adobe», «Microsoft», «Volvo» и другие. По статистике, почти каждый третий человек, который получил интересное сообщение, пересылает его другим людям. Такой метод считается одним из самых эффективных средств скрытого маркетинга.

Говоря об инновационных разработках в области вирусного маркетинга, хочется персонально выделить его составляющие - провокационный (партизанский) маркетинг и buzz-маркетинг (маркетинг шумом). Итак, провокационный маркетинг использует все разновидности коммерческих информационных технологий, а также такие провокационные игры как флэшмобы (flash mob от англ. - «мгновенная толпа») и life placement. Флэшмобы направлены на привлечение внимания толпы зрителей в городской среде, а «лайф плейсмент» внедряет в жизнь определённые сценарии для бренда и создаёт искусственные жизненные ситуации, в ходе которых происходит коммуникация между брендом и потребителем, благодаря чему потребитель приобретает навыки и опыт пользования тем или иным товаром, услугой.

Отдельное внимание стоит уделить продвижению рекламы в социальных медиа и социальных сетях, так как эти ресурсы являются одними из самых используемых в интернет-сфере. Поскольку инновационный маркетинг не стоит на месте, он постоянно разрабатывает новые способы продвижения товаров и услуг в данной перспективной области. Таким образом, основными направлениями являются SMO (Social media optimization) - изменение сайта, SMM (Social media marketing) - маркетинг в социальных сетях и прочих медиа, Social Ads - реклама в социальных сетях. SMO - это комплекс технических мероприятий, совершенствующий контент сайта специально для его оптимизации в социальных сетях. SMM занимается продвижением 
рекламы, товаров и услуг в социальных сетях и является в настоящее время одним из самых перспективных маркетинговых направлений. Social Ads продвигает популярную технику продвижения: он использует информацию профиля пользователя и историю его поисков, чтобы в дальнейшем разместить наиболее релевантные рекламные объявления, подходящие его запросам. С этической точки зрения, данный метод вызывает множество противоречий, так как использует личную информацию пользователя в собственных целях.

Достоинства и недостатки использования инновационного маркетинга в интернете

Проанализировав разновидности инновационного маркетинга в Интернете, можно сделать вывод, что интернет-среда - это один из наиболее значимых факторов мирового развития. Он предоставляет брендам и компаниям огромные возможности продвижения товаров и услуг, обеспечивая относительно низкие цены и надежную всемирную связь глобального масштаба. Благодаря развитию такого информационного пространства, значительно укрепились финансовые, экономические и технологические показатели всемирного хозяйства и его отдельных субъектов, а также нельзя не отметить значительное развитие международного бизнеса. Однако, вместе с активным развитием инновационных интернет-технологий также появились негативные стороны и угрозы, касающиеся трансформации личности. Например, бездумное блуждание по сети может привести к фрагментарному сознанию. Случается это в процессе восприятия пользователем различных подсказок и указателей, ведущих его от одного фрагмента к другому фрагменту. Человек в таких условиях стремится как можно быстрее получить результат и тем самым пропускает логические цепочки, переходя сразу к выводам. Таким образом, людям становится сложнее думать и анализировать самостоятельно, так как эти функции просто постепенно атрофируются. Также, бесцельно пролистывая сеть, человек формирует импульсивность своего поведения и становится впоследствии импульсивным покупателем. Конечно же, маркетологи приветствуют развитие фрагментарного сознания, так как 90\% покупок оцениваются как импульсивные и их мотивы при этом крайне ясны. Но тем не менее, человек должен уметь контролировать свои эмоции и ограждать себя от излишней фрагментарной информации, поскольку это неблагоприятно воздействует на его сознание.

Тенденции инновационных маркетинговых разработок

Поскольку инновационный маркетинг - это крайне динамичная и нестабильная отрасль, в которой постоянно появляется что-то новое, хочется рассказать про тренды инновационных маркетинговых разработок в 2019 году, которые пользуются успехом у маркетологов или имеют потенциал для дальнейшего развития.

Для начала, конечно же хочется отметить, что новый этап развития экономических и маркетинговых технологий тесно связан с «ИИ»искусственным интеллектом [6]. Он постепенно охватывает все сферы человеческой жизни. К примеру, в области производства инновационные нововведения активно вытесняют живую рабочую силу, повышая тем самым уровень безработицы. По этой причине на рынок труда будут внедряться новые профессии, связанные с управлением роботами, их ремонтом и прописыванием для них определённых задач. На сегодняшний день роботы могут создавать новые товары, упаковывать и сортировать их, и даже доставлять в точки продаж или покупателям лично. В ближайшем будущем «ИИ» станет основой современной модели экономики. Так, уже сегодня такие крупные корпорации как Google и Facebook производят монетизацию с помощью потребителей, ведь практически всю их продукцию создают и приобретают сами пользователи. Происходит это просто: с каждым поисковым запросом в Google или кликом по рекламе прибыль корпорации возрастает, хотя пользователи при этом материально ничего не получают. То есть прибыль увеличивается благодаря целому обществу, а приватизируется самому Google. Более того, маркетологи активно используют искусственный интеллект для общения с клиентами и их обслуживания. На многих сайтах можно заметить наличие онлайн-консультантов или чат-ботов, специально запрограммированных для помощи клиентам. Это повышает эффективность работы бренда и качество обслуживания клиентов на дистанционном уровне.

На современном рынке труда замечается тенденция развития квантового маркетинга [5]. Сам квантовый маркетинг представляет собой совокупность различных способов, определяющих наиболее эффективные методы продвижения товаров и услуг. Называется он так потому, 
что активность этой разновидности основывается на «квантовании» - измерении показателей разных каналов по мере их обработки. На данный момент, квантовым маркетингом пользуются такие известные компании как Unilever и Kraft, раннее использовавшие маркетинговые soft skills. Они используют технологии команд обработки и анализа данных, повышающие объем прибыли. Квантование является перспективным направлением, так как оно значительно упрощает работу. В России планируется за пять лет создать специальный квантовый компьютер, возможности которого будут значительно превышать современные устройства. Он сможет решать задачи повышенной сложности и на более качественном уровне, моделировать интеллектуальные способности людей, оперативно распределять логистические потоки, а также создавать материал с заранее прописанными свойствами и синтезировать медицинские препараты. Инвестиции в этот проект должны составить около 900 млн. рублей.

Стоит выделить возрастающую популярность Р2Р-платформ (Peer-to-peer, децентрализованная компьютерная сеть), вызывающую у общественности интерес в связи с тем, что их доверие к государству и глобальным корпорациям падает. Поэтому технология Blockchain стала революционной, особенно для экономической и маркетинговой областей. Цепочка, в которой проводятся транзакции, является защищённой и децентрализованной, что повышает общий уровень доверия. В связи с этим отпадает необходимость использования посредников, чтобы проводить операции для наиболее успешного заключения сделок. Покупатели ожидают, что в скором времени различные бренды и компании станут активно использовать эту систему во всех сферах деятельности, а Blockchain в целом станет прозрачной и доступной технологией. Таким образом, платформы Р2Р позволят каждому человеку безопасно отслеживать заказы, узнавать производителя товара, место производства, следить за ходом судебных дел или заключать договора купли/продажи с отсутствием рисков.
Данная разработка полностью пересматривает систему контроля персональных данных и ставит под сомнение использование cookies, трекинга и других способов онлайн-отслеживания.

Также, замечается интересная тенденция, формирующая новый маркетинговый канал благодаря внедрению беспилотных автомобилей [7]. В прошлом году Uber заказал 24000 автомобилей Volvo, оснащённых автопилотными технологиями. Такие модификации также отмечаются среди моделей Tesla, Audi и Mercedes-Benz. Ho как это связанно с инновациями в маркетинге и созданием абсолютно нового маркетингового канала? Все просто. Водителям больше не нужно будет следить за дорогой, а значит, в это время они смогут потреблять рекламный контент. Некоторые компании уже начали эксперименты в данной сфере, размещая в таких автомобилях различные объявления. Таким образом, рекламные ролики внутри беспилотных авто становятся новой тенденцией продвижения товаров и услуг.

\section{Заключение}

Подводя общий итог, хочется сделать вывод, что все перечисленные виды маркетинга и методы маркетингового продвижения образуют огромную эволюцию не только в сфере инновационных маркетинговых разработок, но и во всем маркетинге в целом, полностью определяя направление его функционирования на сегодняшний день и развития в будущем. Такие нестандартные подходы оказывают максимально эффективное влияние на сознание потребителей и дальнейшее восприятие товара. Если использовать инновации в сфере маркетинга правильно и осознанно, подбирая наиболее эффективные способы под нужные случаи, то компании бесспорно будут обладать рядом преимуществ перед их конкурентами и занимать лидирующие позиции на рынке. Использование инновационного маркетинга, как ни одно другое направление, способно прогнозировать поведение и потребности всех участников рыночных отношений, а также оказывать влияние на их выбор.

\section{Библиографический список}

1. Карпова, С.В. Маркетинг: теория и практика. М., 2012. С. 255-259.

2. Карпова, С.В. Маркетинг и современность: инновационные маркетинговые технологии в модернизации российской экономики. М., 2011.

3. Исследование рынка мобильной рекламы в России в 2017/2018 г. [Электронный ресурc] // iabrus.ru URL: https://iabrus.ru/www/doc/mobile/IAB_Obzor_Mobile_Ad_2018.pdf VRM 
4. VRM Marketing Services [Электронный ресурс] // virtualresortmanager.com URL: https://www. virtualresortmanager.com/marketing-services.asp

5. 18 трендов в маркетинге в 2018 году [Электронный ресурс]// kontur.ru URL: https://kontur.ru/articles/5015

6. 20 трендов технологий и продвижения бренда в 2019 году [Электронный ресурс] // delovoymir.biz URL: https://delovoymir.biz/20-trendov-tehnologiy-i-prodvizheniya-2019-goda.html

7. «MapTex-2018»: что ждать от маркетинговых технологий [Электронный ресурс] // sostav.ru URL: https://www.sostav.ru/publication/na-konferentsii-martekh-2018-rasskazali-chto-zhdat-ot-marketingovykhtekhnologij-31748.html

8. Когнитивный маркетинг: каким будет будущее? [Электронный ресурс] // zen.yandex.ru URL: https://zen.yandex.ru/media/id/5adf4e9a482677a0d28d90cf/kognitivnyi-marketing-kakim-budetbuduscee-5c6a754685460400ae4698a1 